\title{
Use of Videos and Digital Media in Parent-implemented Interventions for Parents of Children with Primary Speech Sound And/or Language Disorders: A Scoping Review
}

\author{
Monica L. Bellon-Harn $\mathbb{1}^{1} \cdot$ Lekeitha R. Morris $^{1} \cdot$ Vinaya Manchaiah ${ }^{1,2} \cdot$ William E. Harn ${ }^{1}$
}

Accepted: 21 September 2020 / Published online: 1 October 2020

(c) Springer Science+Business Media, LLC, part of Springer Nature 2020

\begin{abstract}
No review to date has focused on evaluating the use of videos and digital media in parent-implemented interventions for parents of children with primary language or speech sound disorder (LD/SSD). Research objectives guiding this scoping review included an evaluation of (a) use of videos and/or other digital media in parent-implemented interventions; (b) use of videos and/or other digital media in asynchronous content; (c) the role of the parent as learner; and (d) the program impact on parents and children. This review followed a five-stage framework: (a) identify research questions; (b) identify relevant studies; (c) select studies; (d) chart the data; and (e) collate, summarize and report the results. Ten studies were included. No program included parents of children with speech disorders. One fully asynchronous program was identified, though many programs included videos concurrent with direct instruction. No study described the parent as learner and only four studies examined parent satisfaction and perceptions. These four studies directly measured specific parent behavior and results indicated that the programs had a positive impact on parents' interactions. Nine of the ten studies included child outcomes. This low volume of studies suggests limited work in this area. The review describes research gaps and future directions.
\end{abstract}

Keywords Parent-implemented $\cdot$ Communication disorders $\cdot$ Digital intervention $\cdot$ Speech sound disorders $\cdot$ Language disorders

\section{Highlights}

- Parent-implemented interventions using asynchronous instructional content indicate promise.

- Parent-implemented interventions for children with LD/SSD infrequently use asynchronous instructional content.

- Evaluations of programs using self-managed or asynchronous instructional content is lacking.

Language disorders (LD) in children refer to significant impairment in the acquisition and use of language across modalities due to deficits in comprehension and/or production across any of the five language domains (i.e., phonology, morphology, syntax, semantics, pragmatics) (Owens 2014). Speech sound disorders (SSD) in children refer to any difficulty with perception, motor production,

Monica L. Bellon-Harn

mlharn@lamar.edu

1 Department of Speech and Hearing Sciences, Lamar University, Beaumont, TX, USA

2 Department of Speech and Hearing, School of Allied Health Sciences, Manipal University, Manipal, Karnataka, India and/or phonological representation of speech sounds that impact speech intelligibility (Bernthal et al. 2017). Although prevalence data is problematic due to sampling issues and methods used to identify LD and SSD, prevalence data for children with LD range from 2.81 to $16 \%$ in children 7 years and younger (Law et al. 2000). Estimates of SSD range from 2 to $25 \%$ of children ages 5 to 7 and $3.6 \%$ beyond 8 years of age (Law et al. 2000; Wren et al. 2016). In a study of 24-month-old children, Zubrick et al. (2007) found a prevalence estimate of $13.4 \%$ for late language emergence (LLE), a condition considered to be the first diagnostic symptom of children with language impairments. Further, preschool children with LD often present with SSD concurrently, which complicates the prevalence numbers and compounds the communication difficulties (Haskill and Tyler 2007; Shriberg et al. 1986; 
Shriberg et al. 1999). Primary LD and/or SSD (LD/SSD) in preschool years have a significant long-term impact on later communication further in life and academic success (Felsenfeld et al. 1992; McCormack et al. 2011; Norbury and Bishop 2003). Future difficulties in language and literacy may be mitigated or prevented through the use of parentimplemented interventions with their young children (DeVeney et al. 2017; Roberts et al. 2019).

Inclusion of parents in the intervention process supports positive outcomes for their children (Kaiser and Hampton 2017; Zevenbergen and Whitehurst 2003). Through a variety of validated methods (e.g., didactic instruction, instructional/evaluative video, group discussions) parents can be trained to facilitate their child's speech and language development (Roberts and Kaiser 2011; Sugden et al. 2016). Protocols vary in terms of approaches and strategies; however, the effectiveness of parent-implemented interventions is related to the active role of the parent as learner and facilitator (Hart and Risley 1995). Research suggests that parents vary in their facilitative language techniques and responsiveness according to several factors including children's language abilities and parents' educational level and socioeconomic status (Christian et al. 1998; Heath 1982; Kuo et al. 2004; Lyytinen et al. 1998). That said, nearly all parents support their children's language skills (Girolametto et al. 1996; Tamis-LeMonda et al. 2001).

Parent-implemented interventions described as triadic interventions may facilitate parent's use of supports. In this type of intervention clinicians can teach parents to implement strategies that improve their child's speech and language (Brown and Woods 2015). Elements of the triadic interactions include creating a supportive context to promote parent-child engagement and teaching a range of strategies to strengthen the parent-child interactions (McCollum and Yates 1994). A triadic intervention facilitates provision of care that respects and reacts to needs, values, and preferences of families follows a familycentered approach (Manolson 1992). Shared knowledge and responsibility within the therapeutic relationship promote family-centeredness and encourages greater involvement and accountability. Success of parent-implemented interventions may partially be linked to parents' empowerment to take an active role in their child's development (Epstein and Street 2011).

Effective parent-implemented interventions are not accessible to all families in the United States who need them. There are not sufficient trained personnel to serve the growing number of children eligible for early intervention services due to state fiscal issues (Cason et al. 2012). In particular, rural locations may experience a shortage of trained personnel (Cason 2009). The negative impact is compounded since families residing in rural communities also lack access to healthcare including health promotion and prevention services. Additionally, these families have lower socioeconomic status and complete less education (i.e., no high school diploma or a high school diploma/ equivalency). The recent pandemic further underscores the need for accessible programs.

One way to increase access is to utilize programs that include videos and digital media in asynchronous content (i.e., content is provided for the parents to complete independently), which is cost effective and may result in positive outcomes (Andersson 2018). Such programs do not rely on direct, in-person service delivery. Use of videos and digital media may be included in fully asynchronous programs or a combination of asynchronous content with direct instruction. Emerging data on parent-implemented interventions using asynchronous instructional content indicate promise. For example, a fully asynchronous, internet-based intervention in stuttering may be beneficial for instructing parents about identification of stuttering, knowledge about conducting practice sessions, and how to present intervention strategies as a part of the Lidcombe Program (van Eerdenbrugh et al. 2018). In the domain of telehealth, parent-implemented interventions may include synchronous content in which the content is presented in real-time albeit geographically distant as well as asynchronous content in which content is provided for the parents to complete independently (e.g., online module) (Snodgrass et al. 2017). For example, telehealth training of the Early Start Denver Model (i.e., a behavioral approach for children with autism) with both synchronous and asynchronous content (e.g., email, instructional modules) facilitated higher parent fidelity gains and program satisfaction than an in-person, treatment-as-usual group (Vismara et al. 2018).

Utilization of asynchronous instructional content within parent-implemented intervention protocols introduces new considerations for program development and evaluation. Elements contributing to the effectiveness of fully self-managed internet-based programs include (1) the use of evidence-based content; (2) an interactive, self-management approach; (3) guided support; and (4) secured and user-friendly platform (Ritterband et al. 2009; Beukes et al. 2016). Elements contributing to successful telehealth include (1) performing synchronous or asynchronous services with modifications; (2) ensuring that an appropriate facilitator is available; and (3) assuming responsibility for ensuring the client's safety during telehealth (Richmond et al. 2017). Over time, innovations and research related to asynchronous instructional content will continue to enhance and shape our program development and evaluation (Andersson 2018).

As noted, the effectiveness of parent-implemented interventions is related to the role of the parent as learner and facilitator. In programs that include asynchronous instructional content or are fully self-managed, the role of the parent as learner and the impact of the training on parent 
outcomes is a unique consideration. The adult learning theory of Knowles et al. (2005) describes components of adult learning which may be critical in a self-managed and asynchronous digital learning environment. These include (1) adults need to know why they need to learn something; (2) adults maintain responsibility for their decisions and lives, (3) adults enter the educational activity with varied experiences; (4) adults want to learn things that they need to know in real-life situations; and (5) adults are more responsive to internal motivators than external motivators. In application, the impact of instructional content may be most effective when self-reflection and self-directed learning activities as well as videos of real-world examples are utilized (Cook and Dupras 2004; Cummins and Hulme 1997; Leong et al. 2003). Further, content may be beneficial when it is immediately relevant (i.e., learning occurs in the same context in which it is applied).

In light of the potential impact of videos and digital media in asynchronous parent-implemented interventions, we examined the evidence of parent-implemented interventions that include asynchronous instructional content or self-managed programs in the form of videos or digital media for parents of children with primary LD/SSD. Research objectives guiding this scoping review included understanding (a) use of videos and/or other digital media in parent-implemented interventions; (b) use of videos and/or other digital media in asynchronous content; (c) the role of the parent as learner; and (d) the program impact on parents and children.

\section{Method}

A scoping review methodology is reported to be an effective approach to examine areas with emerging evidence
(Arksey and O'Malley 2005). This review followed a fivestage framework: (a) identify research questions; (b) identify relevant studies; (c) select studies; (d) chart the data; and (e) collate, summarize and report the results.

\section{Identify the Research Questions}

A broad research question was identified to explore an overarching topic (i.e., How do parent-implemented interventions for children with LD/SSD utilize videos and/or digital media in asynchronous instructional content within telehealth programs or self-managed programs?). This question was combined with two specific 'scope of inquiry' question as suggested by Levac et al. (2010) (i.e., What is the role of the parent as learner? and What is the program impact on parent and child outcomes?). These questions clearly define the population and concept of interest.

\section{Identify and Select Studies}

The inclusion and exclusion criteria were developed with reference to the PICO template (i.e., Participants, Intervention, Controls, Outcome Measures) criteria as detailed in Table 1. Study design was also included. The literature search was undertaken between August 2018 and December 2018. The search was conducted on the following electronic databases: Medline (PubMed), CINAHL Complete, and PsycINFO. In addition, a manual search was conducted on the following journals: International Journal of SpeechLanguage Pathology, International Journal of Language and Communication Disorders, Child Language Teaching and Therapy, Journal of Speech, Language, and Hearing Research, American Journal of Speech-Language Pathology, British Medical Journal.

Table 1 Inclusion and exclusion criteria

\begin{tabular}{lll}
\hline Study characteristic & Inclusion criteria & Exclusion criteria \\
\hline $\begin{array}{l}\text { Study type } \\
\text { Participant }\end{array}$ & $\begin{array}{l}\text { Any study design which evaluated the outcome of intervention } \\
\text { Parents of children (birth to 12 years) with primary speech sound } \\
\text { disorder and/or language disorder } \\
\text { Parent implemented programs with some digital media component(s) }\end{array}$ & $\begin{array}{l}\text { Opinion and summary articles } \\
\text { Children with other disorders and not directly } \\
\text { related to speech and language }\end{array}$ \\
& $\begin{array}{l}\text { including but not limited to: apps, internet based, telehealth, and } \\
\text { videotape recording }\end{array}$ & \\
Intervention/comparison & $\begin{array}{l}\text { Any comparative intervention is permitted } \\
\text { Outcomes/data type }\end{array}$ & Quantitative/qualitative \\
Language & Published in English & $\begin{array}{l}\text { Languages unable to be interpreted due to } \\
\text { unfamiliarity of scoping review authors }\end{array}$ \\
Publication type & $\begin{array}{l}\text { Published or accepted for publication in peer-reviewed academic } \\
\text { journals }\end{array}$ & $\begin{array}{l}\text { Unpublished materials Editorials Articles in } \\
\text { professional journals Thesis/Dissertations }\end{array}$ \\
Publication date & 1986-2018 & \\
Setting & Any geographical location &
\end{tabular}

The first digital format of video was introduced in 1986, so we excluded studies prior to 1986 
Fig. 1 Flow diagram of the study identification, eligibility search, and inclusion process

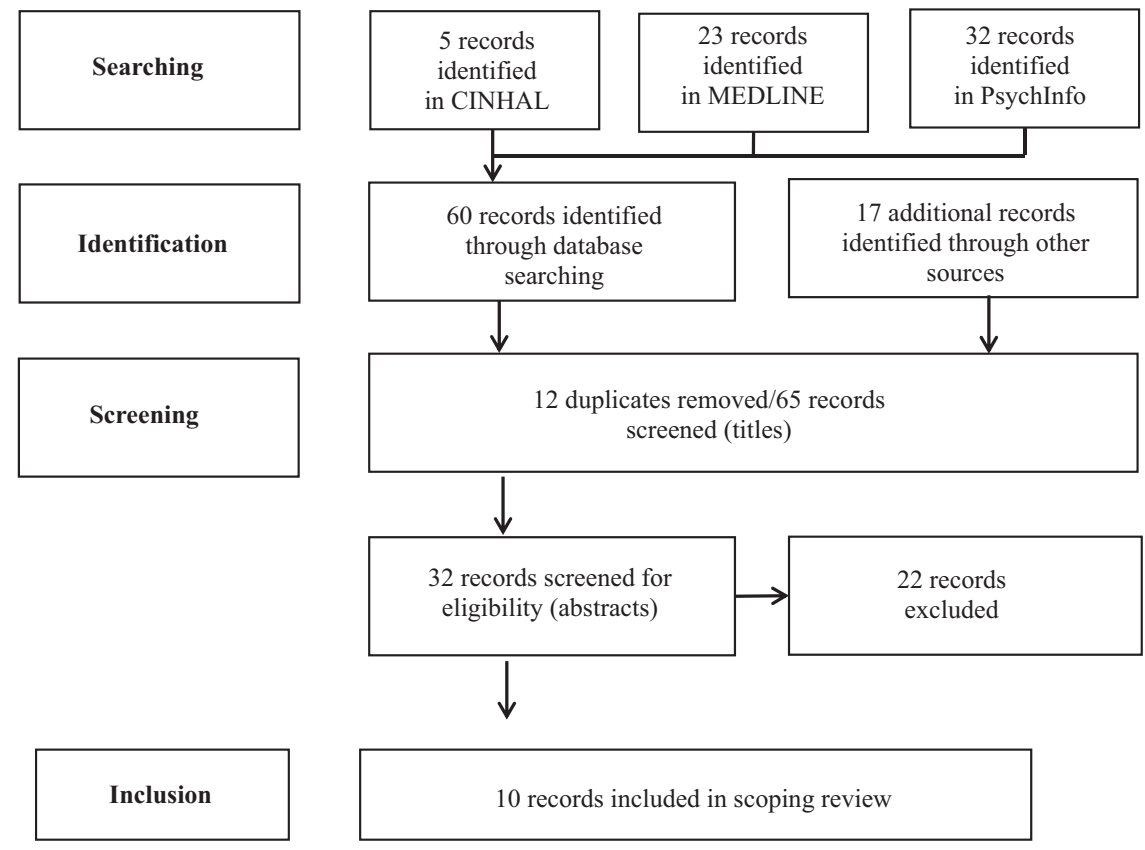

The selected search terms related to the population included parents $[\mathrm{MeSH}]$, language disorders $[\mathrm{MeSH}]$, speech sound disorders $[\mathrm{MeSH}]$, and child $[\mathrm{MeSH}]$. The selected search terms related to the intervention included parent-implemented intervention, parents education $[\mathrm{MeSH}]$, parents program, parent-mediated intervention, parents role, and family centered care. Other selected search terms related to the intervention included video, telemedicine $[\mathrm{MeSH}]$, telehealth $[\mathrm{MeSH}]$, teleeducation, eHealth $[\mathrm{MeSH}]$, digital, internet, mobile applications, online, self-guided.

The search string included: speech sound disorders OR language disorder OR phonological disorder OR apraxia AND Child AND parents AND parent-implemented intervention OR education OR program OR parent-mediated intervention OR parents role OR family centered care AND video OR e-health OR digital OR Internet OR mobile applications OR online OR self-guided OR telemedicine OR telehealth OR teleeducation OR telepractice.

Seventy-seven records were screened against the inclusion/exclusion criteria. After duplicates were removed, 65 records were screened. The first author screened the titles and 33 records were excluded. The first and second authors then independently screened the abstracts of the remaining 32 records and 22 records were excluded. A total of 10 articles were included in this review (See Fig. 1).

\section{Charting the Data}

A PICO template and specific information related to the research questions were used to chart the data. PICO is widely used to frame clinically relevant questions (Orlikoff et al. 2015). The recorded information was study and location, participants, intervention type, fidelity and duration, controls, outcome measures, and study designs. Three authors independently described the PICO criteria. Responses were compared and discussed in an iterative process.

\section{Participants}

These studies included parent-child dyads ranging in age from 11 months to 10 years (See Table 2). While all children were identified with language difficulties, delays, or disorders, no common inclusion criteria were noted. Further, no children were identified with SSD. Of the studies, five did not provide detailed parent demographic characteristics (Allen and Marshall 2011; Falkus et al. 2016; Konza et al. 2010; Olson et al. 2016; Wake et al. 2011). Five studies provided some limited demographic detail about the participating parents and children. Two included parents who had a high-school degree or higher, were considered middle class, and were in their mid-30s (Girolemetto et al. 1996; Roberts and Kaiser 2012). Baxendale and Hesketh (2003) indicated that a majority of parents had a minimum of 16 years of education and only two had education beyond 18 years. Children in van Balkom et al. (2010) were part of a two-parent family with the mother as the main caretaker. All families had a middle-class socioeconomic status. Pratt et al. (2015) included both demographic details of the parents (i.e., all mothers, monolingual speakers of Spanish, high-school graduates, upper middle class) as well as home literacy behaviors (i.e., parent reading practices with their children). One study included a large sample of parent-child dyads (i.e., 285) from diverse 


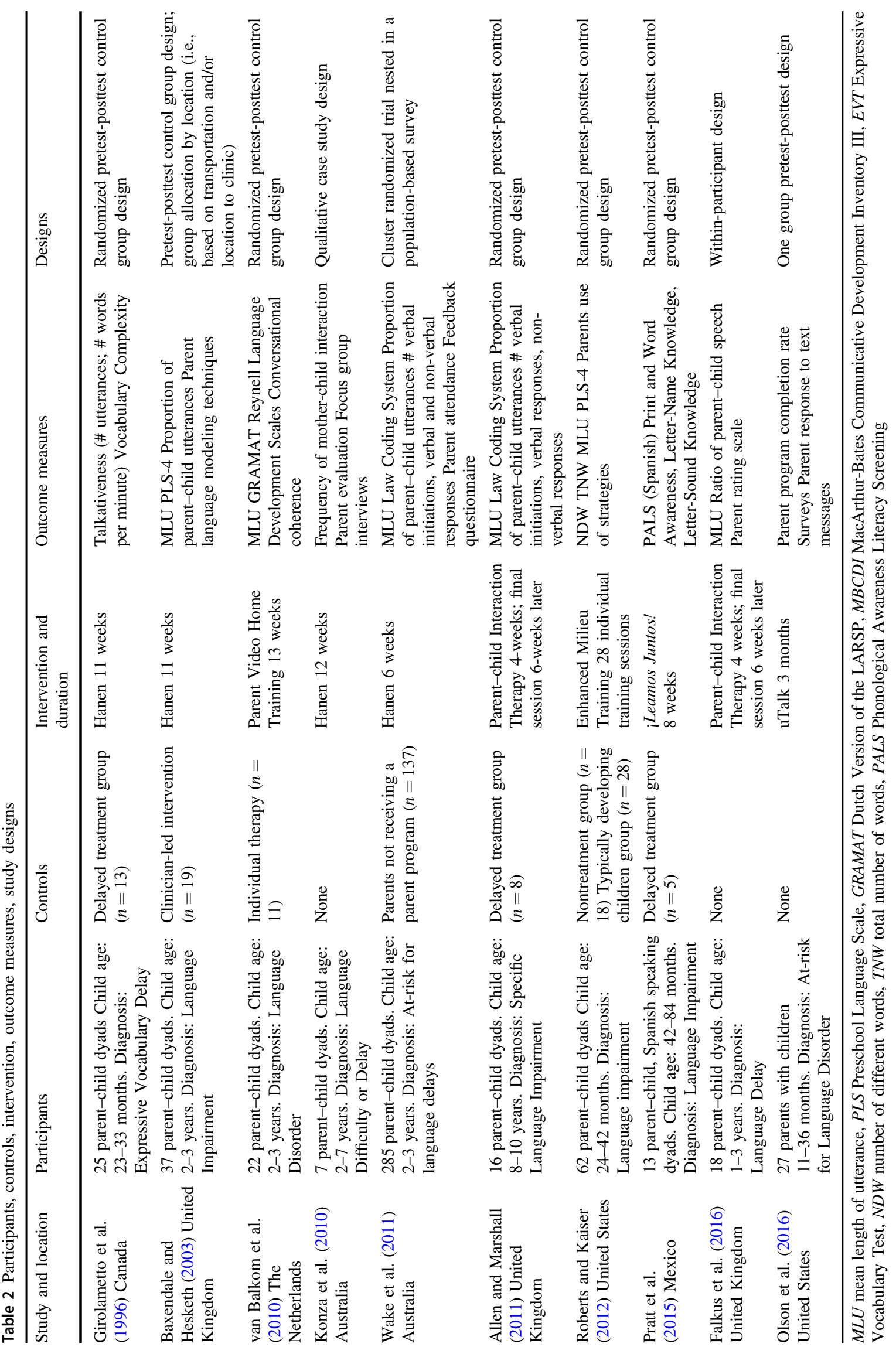


locations within Australia (i.e., Wake et al. 2011). The other nine studies had smaller sample sizes, ranging from as many as 62 to as few as 7 parent-child dyads. Both Falkus et al. (2016) and van Balkom et al. (2010) noted high individual variation in language abilities among their child participants.

The location of where the studies were conducted varied. Girolametto et al. (1996) was conducted in Canada. Baxendale and Hesketh (2003), Allen and Marshall (2011), and Falkus et al. (2016) were conducted in the United Kingdom. van Balkom et al. (2010) was conducted in The Netherlands. Wake et al. (2011) and Konza et al. (2010) were conducted in Australia. Roberts and Kaiser (2012) and Olson et al. (2016) were conducted in the United States. Pratt et al. (2015) was conducted in Mexico.

\section{Intervention type, duration, and fidelity}

Table 2 identifies the intervention type used in each study and the duration of the intervention. Nine studies included investigations of validated parent-implemented interventions (i.e., Hanen Program, Enhanced Milieu Teaching, Parent-child Interaction Therapy, Parent Video Home Training, and ;Leamos Juntos!). One study piloted a fully self-managed digital program (i.e., uTalk) to examine the impact of text messaging (Olson et al. 2016). Varying levels of intervention intensity ranging from 4 weeks to 3 months were reported. Roberts and Kaiser (2012) did not report total treatment time, but the parents were provided 28 sessions. Two of the ten studies reported on the steps they implemented to achieve high treatment fidelity. Other investigators described the parent training and instructions provided but did not report measures of treatment fidelity. Van Balkom et al. (2010) noted the difficulty in controlling for the recommendations and tips provided to parents during home visits, and Olson et al. (2016) stated that they did not assess whether parents participated in the suggested activities they provided via text messages in their study.

\section{Control}

Three studies compared the intervention group to a delayed treatment group (Allen and Marshall 2011; Girolametto et al. 1996; Pratt et al. 2015). See Table 2. Three studies compared the intervention group to another intervention. Baxendale and Hesketh (2003) included a control group of children participating in one-to-one conventional therapy without Hanen training. van Balkom et al. (2010) included a control group characterized as an individualized direct child language intervention in which parent involvement was not included. Wake et al. (2011) included one control group of parents not receiving a parent based program. Roberts and Kaiser (2012) included one control group of typically developing children and one control group of children with language impairment who were not receiving treatment. Three studies did not include control groups (Falkus et al. 2016; Konza et al. 2010; Olson et al. 2016).

\section{Outcome measures}

Table 2 presents outcome measures used in each study. The majority of studies utilized parent outcome measures consisting of metrics derived from analyzing videotaped parent-child interactions and ad hoc questionnaires and scales. Two studies did not include parent outcome measures (van Balkom et al. 2010; Pratt et al. 2015). Nine of the studies examined program effects on child outcome measures and used metrics derived from analyzing videotaped parent-child interactions and from administering established psychometric instruments. There were no specific outcome measures common to all studies. Of the studies that included metrics during parent-child interaction, four examined the relationship between parent and child productions (Allen and Marshall 2011; Baxendale and Hesketh 2003; Falkus et al. 2016; Konza et al. 2010). The majority of studies focused on short-term outcomes. Only Wake et al. (2011) and Baxendale and Hesketh (2003) collected data from observation points at least 12 months apart.

\section{Study design}

Three studies did not include control groups (See Table 2). Falkus et al. (2016) used a within-participant design, Konza et al. (2010) used a qualitative, individual case report, and Olson et al. (2016) used a one group pre-post-test design. Four studies used a pre-post-test design with random assignment to a treatment or non-treatment control group (Allen and Marshall 2011; Girolametto et al. 1996; Pratt et al. 2015; Roberts and Kaiser 2012). One study used a cluster randomized trial (Wake et al. 2011). Baxendale and Hesketh (2003) used a pre-post-test with allocation by location (i.e., based on transportation and/or location to clinic) to a parent-implemented intervention or a direct child intervention. van Balkom et al. (2010) used a pre-post-test design with random assignment to a parent-implemented intervention that emphasized video training or a direct child intervention or individual therapy.

\section{Collating, Summarizing, and Reporting the Results}

Information related to the research questions (e.g., role of videos and digital media; role of parent as learner within the intervention; impact on parent and child) were collated and summarized. Three authors independently described the study characteristics and summarized studies according to the research questions. Responses were compared and discussed in an iterative process. 


\section{Results}

\section{Role of Videos and Digital Media}

The first two research questions were concerned with the role of videos and digital media and how it was used. In particular, we were interested in how videos and digital media were used in asynchronous instructional content or self-managed programs (See Table 3). One study piloted a fully self-managed digital program (i.e., uTalk) to examine the impact of text messaging (Olson et al. 2016). The other nine studies using validated programs targeted parent interactional strategies and included videos. van Balkom et al. (2010) used videos as a core component of Parent Video Home Training. Videos included positive conversations between the parent and child that were shown and discussed with certified trainers. Allen and Marshall (2011) and Falkus et al. (2016) also used videos as a core component of Parent-child Interaction Therapy to allow parents to observe and formally analyze how they interact with their child using a self-rating scale. Girolametto et al. (1996), Baxendale and Hesketh (2003), Konza et al. (2010), Wake et al. (2011) included videos as a part of Hanaen program in which parents were videotaped interacting with their children during home visits and the videotapes were used to provide immediate feedback and on-the-spot coaching was provided as necessary. Roberts and Kaiser (2012) used videos when introducing new topics in an hour-long workshop to provide examples of target strategies. Pratt et al. (2015) used videos in a similar manner. It is notable that Pratt el al. (2015) examined a Spanish version of an English validated program to train parents of children on shared book reading strategies (Pratt et al. 2015). Overall, the interventions used videos concurrent with varying levels of direct support, not specifically as asynchronous instructional content. It is not noted if the videos were left with the family to review and discuss independently of the trainers.

\section{Role of the Parent as Learner}

The second research question was concerned with how the role of the parent as learner was detailed in the design of the programs or in the outcomes (See Table 3). Although all interventions were based on training parents, no study explicitly described or studied the role of the parent as the learner. That said, adult learning principles are components of the Hanen Program and central to the Hanen Program.

\section{Program Impact on Parents and Children}

Table 4 presents the summary of outcomes of the eight studies that included parent outcomes. Three studies without control groups reported change in parent behavior.

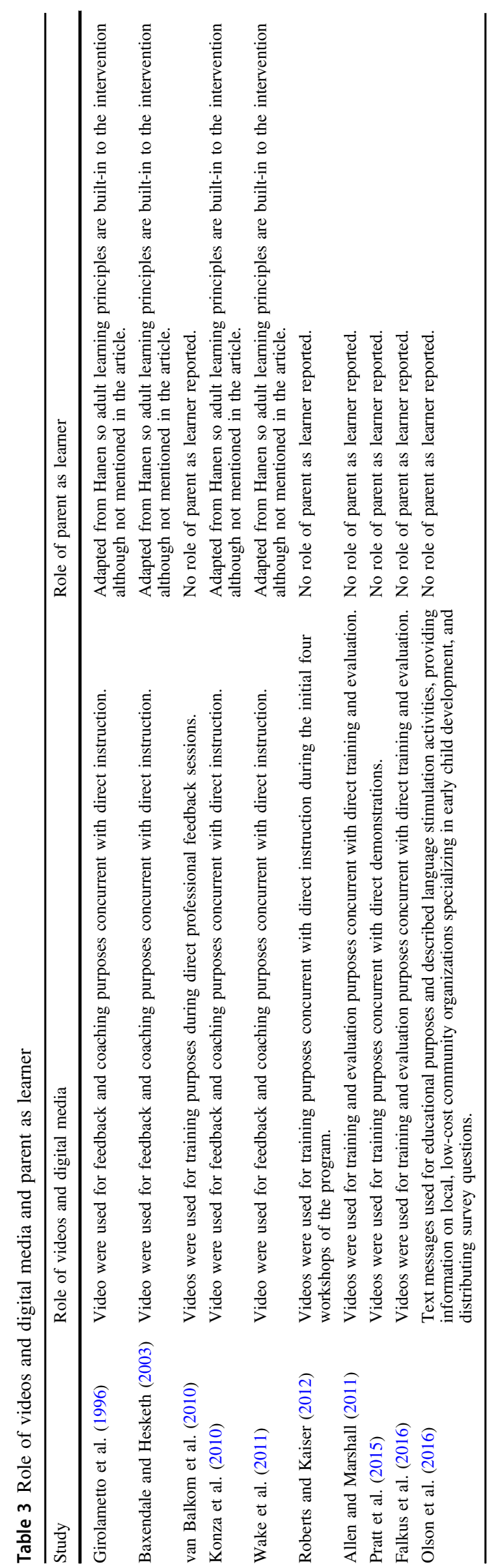




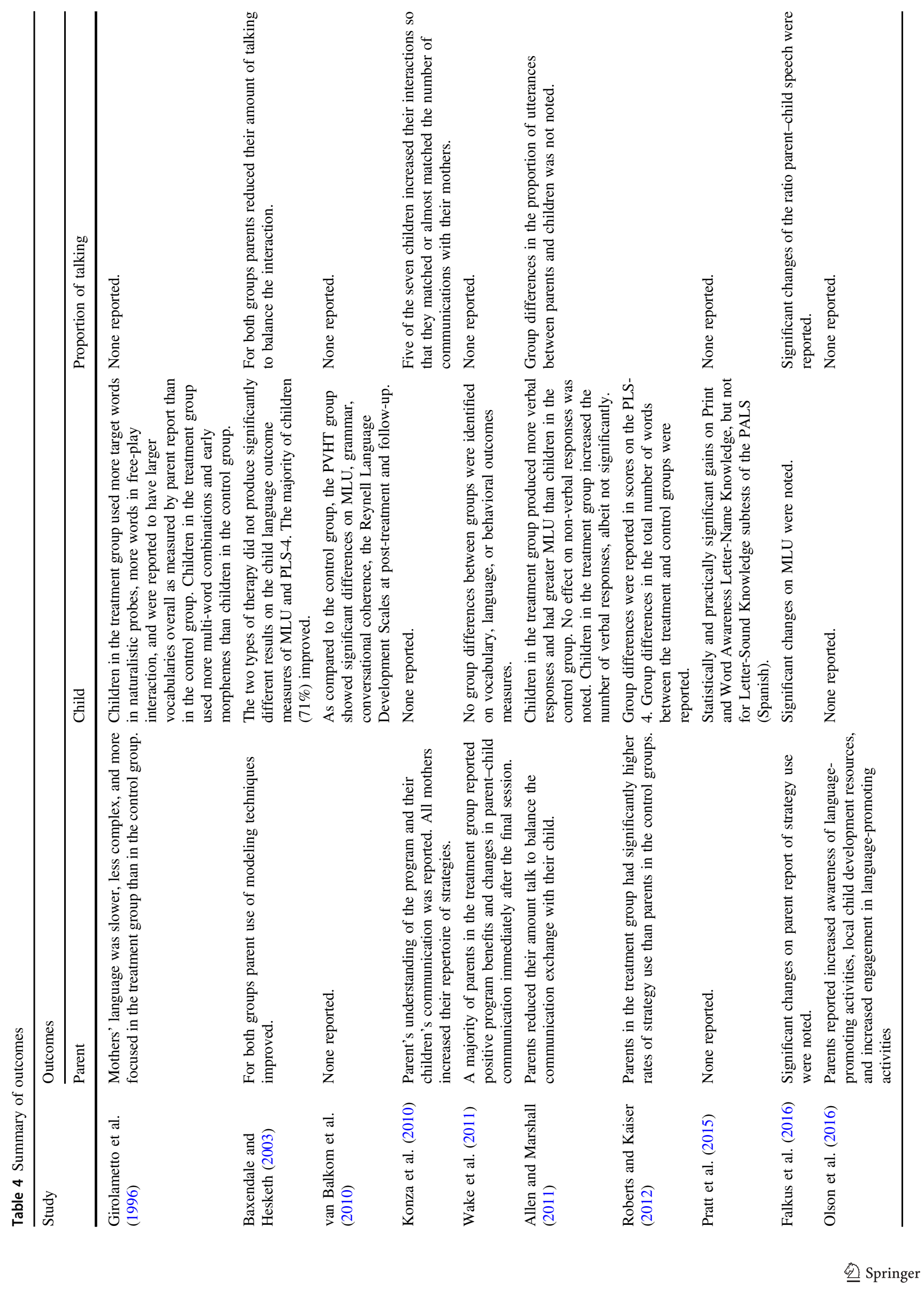


Faulkus et al. (2016) reported that significant change occurred in the parent rating scale, which is a scale used by parents to rate their performance. The significant changes in the ratio of parent and child utterances indicated that parents reduced the time they spoke and children increased the time they spoke. In Konza et al. (2010) seven parents reported understanding the program and their children's communication on a 6-item evaluation questionnaire and focus group transcripts. Parents in Olson et al. (2016) reported via a survey an increased awareness of language-promoting activities and local child development resources as well as an increased engagement in language-promoting activities and selfreported knowledge (i.e., I know about activities that help my child learn to talk; I know places in the community where I can go to help my child learn to talk). All of the parents reported that they enjoyed the program and would recommend to other families, $96 \%$ considered it valuable to their family, and $89 \%$ reported that the program helped their child.

Two of the four studies comparing a parent-implemented intervention to a non-treatment control group indicated group differences on parent outcomes. Girolametto et al. (1996) reported significant group differences on mothers' number of words per minute, target words, and focused stimulation strategies in that mothers in the treatment group used fewer words, more target words and more focused stimulation than the control group. Roberts and Kaiser (2012) reported that parents in the treatment group had significantly higher rates of enhanced milieu teaching strategies than parents in the control groups. Allen and Marshall (2011) reported a treatment effect on the proportion of child to parent utterances; however, no group differences were reported.

Two of the three studies comparing a parentimplemented intervention with a treatment control group reported positive parent outcomes. In Wake et al. (2011), a majority of parents in the treatment group reported positive program benefits and changes in parent-child communication immediately after the final session. Specifically, 86 of the 100 parents in Wake et al. (2011) that were asked to give feedback believed the program had led to positive changes in how they communicated with their children. Seventy-two of the parents reported positive changes in their children's communication, 62 reported changes in their children's behavior, and 47 parents who had other children reported benefits in how they communicated with them. Although Baxendale and Hesketh (2003) did not report group differences on frequency of parent use of modeling techniques or ratio of parent utterances to child utterances, for both groups the ratio of parent-child utterances equalized, and parents used more expansions and imitations.

Nine studies reported child outcomes (See Table 4). Two of the studies without control groups reported change in child behavior. Faulkus et al. (2016) reported that significant change occurred in child mean length of utterance.
Konza et al. (2010) reported that five of the seven children increased their interactions so that they matched or almost matched the number of communications with their mothers. Olson et al. (2016) did not have a control group and child outcomes were not reported.

Of the studies comparing a parent-implemented intervention to a control group, four reported group differences on child outcomes. Girolametto et al. (1996) reported that children in the treatment group used more target words in naturalistic probes, more words in free-play interaction, and were reported to have larger vocabularies overall than in the control group as measured by parent report. Children in the treatment group used more multi-word combinations and early morphemes than children in the control group. Pratt et al. (2015) reported that children's print knowledge skills (e.g., understanding letters and sounds) changed significantly over the duration of the study in both the treatment and control group. Group differences were indicated for print and word awareness and letter-name knowledge, but not for letter-sound knowledge. In Roberts and Kaiser (2012) group differences were reported in scores on the PLS-4 and the total number of words. Although Allen and Marshall (2011) reported a treatment effect on number of verbal initiations and child mean length of utterance, no group difference were reported. No differences were noted on the number of verbal responses or non-verbal responses.

Of the three studies comparing a parent-implemented intervention with a treatment control group, van Balkom et al. (2010) found significant group differences on MLU, grammar, conversational coherence, and the Reynell Language Development Scales at post-treatment and follow-up. Wake et al. (2011) and Baxendale and Hesketh (2003) did not report group differences on any child outcome measure.

\section{Discussion}

Access to parent-implemented interventions can be increased through interventions that do not require direct, in-person service delivery. This scoping review drew together 10 studies related to the use of videos or digital media within parent-implemented programs for parents of children with LD/SSD. This low volume of studies suggests there is limited work in this area as compared to other areas of communication disorders (i.e., stuttering, hearing loss, autism). With regard to the first question, only one program utilized self-managed instructional content (Olson et al. 2016), and no program utilized asynchronous instructional content within telehealth programs. Overall, the programs in this review included instructional and evaluative videos concurrent with varying degrees of direct instruction and support. It is noteworthy that no study in this review included parents of children with SSD. 
With regard to the second and third questions, no study explicitly described the parent as learner, though adult learning principles are built into the Hanen program. Eight studies examined parent outcomes; however, only four studies included measures of parent perception and satisfaction. Results of these studies suggested parents felt a sense of empowerment following training, which is an important adult learning principle. For example, in Falkus et al. (2016) parents were empowered by being asked to select the strategy they would like to address, to comment on their use of the interaction strategies, and to comment on the impact they felt it has had on their child's communication. Participants in Olson et al. (2016) reported an enhanced sense of competence and self-worth, which has been linked to empowerment (Friedman et al. 2012; Prelock and Hutchins 2008). Four studies directly measured specific parent behavior and results indicated that the programs had a positive impact on parents' interactions.

Results indicated that when no control group was used or when compared to no treatment, parent-implemented interventions had greater gains on both parent and child outcomes. However, two programs that compared a parentimplemented intervention to direct child intervention did not report group differences (i.e., Wake et al. 2011; Baxendale and Hesketh 2003). Wake et al. (2011) note the children in this study were between 2 and 3 years of age and suggest that perhaps prevention activities should happen at an earlier age. vanBalkom et al. (2010) compared Parent Video Home Training, which included videos as a dominant training component, to direct child intervention with parents of children between 2 and 3 years of age. Greater gains on child outcome measures were reported for the group enrolled in the Parent Video Home Training intervention.

\section{Research Gaps}

The reviewed articles suggest infrequent use of videos and/ or other digital media in asynchronous instructional content or self-managed programs within parent-implemented interventions for children with $\mathrm{LD} / \mathrm{SSD}$. If a program design includes self-managed or asynchronous instructional content, analysis of the program's use of evidence-based content, a self-managed approach, guided support, and a secure, user-friendly platform is critical (Ritterband et al. 2009). Olson et al. (2016) was a pilot study designed to evaluate uTalk, a text-based program. Information related to the validity of uTalk, guided supports, or security or usability of the platform was not included. Further, outcome measures were non-validated surveys that appeared to be limited in their sensitivity to measure parental behavior. Overall, evaluations of programs using self-managed or asynchronous instructional content is lacking.

Videos were used to deliver information for education purposes (Olson et al. 2016), provide direct instruction on strategies (e.g., Pratt et al. 2015), and provide evaluative feedback (e.g., van Balkom et al. 2010). Roberts and Kaiser (2012) noted that, "teaching specific strategies using individualized video examples provided the initial foundation by teaching parents why and how to use each strategy" (p. 14). Eighty-eighty percent of the parents in Wake et al. (2011) reported that watching their own video clips was useful and $87 \%$ shared that getting feedback on their interactions with their child during the session was helpful. Konza et al. (2010) reported that all of the parents felt that watching the videos of themselves and receiving feedback from a professional was very helpful. The use of online video recordings for various purposes may hold significant promise and is well suited for digital parent-implemented interventions. More research examining the impact of videos across various treatment protocols is needed.

Knowles et al. (2005) described multiple adult learning principles, each of which could be included in measures of parents' perceptions of a parent-implemented intervention. As noted, parent perception and satisfaction outcome measures in this review were in part linked to a sense of empowerment and the principle that adults are more responsive to internal motivators than external motivators. However, the role of adult as learner within such programs is understudied. Other questions should explain how well the intervention describes for parents of young children the relevance of the intervention, allows parents to maintain responsibility for their learning, includes activities with varied and meaningful experiences, and motivates parents to continue with the program. These constructs are linked to adult learning principles that contribute to successful intervention completion. Further, formative and summative evaluation of parents' perceptions should be included as outcome measures to ensure the information is accessible and beneficial from the families' perspective. Finally, most of the studies in this review did not include long-term outcome measures though several of the authors called for longer-term follow-up data. It is critical to understand the immediate impact of the program as well as whether or not families continue to apply the strategies and expand their knowledge.

The studies in this review did not include diverse populations. Although the studies were conducted in various geographical locations, there is very little diversity in terms of race/ethnicity, education level, or socioeconomic status. The studies that reported parental demographics described parents as educated and from middle-upper socioeconomic status. As noted, parents vary in their facilitative language techniques based on several factors including educational level and socioeconomic status (e.g., Heath 1982). Further, families residing in rural locations may have less access to resources. Since digital programs may be a solution to meet the needs of families residing in 
rural locations (Cason 2009; Cason et al. 2012) programs need to be evaluated with regard to family and community resources. For example, researchers would need to ensure that internet availability would not create a barrier to access these programs and create ways to eliminate this barrier.

\section{Future Directions}

As noted, elements contributing to the effectiveness of selfmanaged digital programs include the use of evidence-based content (Richmond et al. 2017; Ritterband et al. 2009). In other words, digital programs should utilize validated interventions while varying the delivery modality. For example, Snodgrass et al. (2017) described reframing direct child interventions into parent coaching interventions through telehealth. As such, evaluation of digital programs based on validated interventions should strive to understand how the digital modality impacts parent learning and child outcomes. For example, van Eerdenbrugh et al. (2018) employed the Internet to deliver the Lidcombe Program and assessed the parents' knowledge about the disorder and how to conduct interactions and sessions. As programs move further into the digital realm, it is critical that the role of the parent as learner and facilitator is fully explicated. Surveys that examine perceived motivation or competence may be beneficial in understanding the digital service delivery (e.g., Intrinsic Motivation Inventory, Deci and Ryan 1982; Perceived Competence Scale, Williams and Deci 1996).

Overall, long-term outcomes of parent-implemented interventions are needed. Interventions with asynchronous instructional content or self-managed content may have unique challenges obtaining short- and long-term follow-up measures. Attrition can be a challenge for digital programs since the direct contact between clinician and parent may not be established or may be intermittent. In order to facilitate retention, parents should be able to contact the clinician via computer-mediated contact (e.g., chat function; secured email) to get clarification about the content and request additional content (Buekes et al. 2016). Parents should be prompted to request more information and push notifications and reminder email could prompt participants to complete specific activities (e.g., request for complete a questionnaire, complete an activity). For parents who may have limited internet access, text messaging could be an avenue to use for these same reminders and requests for information. Such strategies may facilitate completion through post-program and follow-up data collection and provide needed information regarding long-term impacts of parent-implemented intervention. However, research regarding these strategies as design features for retention through short- and long-term data collection are needed.

Video may be a necessary component of a digital parentimplemented intervention (Cummins and Hulme 1997). In a digital realm multiple instructional purposes could be addressed and examined (i.e., deliver information related to the disorder, provide direction instruction on strategies, provide evaluative feedback). For example, video reflective activities could allow the parent to not only learn a new concept, but to reflect on what the information really means and how they may use the strategy with their child. Additionally, active engagement can be done through interactive videos embedded within the program. Skills adults learn must be immediately relevant and applicable with positive effects (Knowles 1984). Helping parents connect information in the parent-implemented intervention with direct relevance to their child's life can be done through video examples and testimonials.

Access to digital programs may increase sample diversity; however, online recruitment presents its own challenges. Researchers developing and evaluating digital parent-implemented interventions will need to consider how to ensure a representative sample in recruitment phases. For example, researchers may recruit on Facebook groups dedicated to parenting children with disabilities or use specific Twitter hashtags to identify specific parent groups (Thornton et al. 2016).

Finally, instructional protocols of digital programs will have unique variables (e.g., technological competencies of the user, nature of online instruction) beyond the intervention itself. As parent-implemented interventions increase the degree to which the instruction is digital, the interface between the parent and the program will need to be examined (Richmond et al. 2017; Ritterband et al. 2009). Questions considering the parent's perception of the provision of an intuitive and interactive system, messages from the clinician or platform administrator, and/or online help should be asked.

\section{Limitations}

Scoping studies intend to chart relevant literature in a particular area of interest and identify gaps in current research. One limitation is that quality assessments are not conducted. Although we searched electronic databases and journals for peer-reviewed studies, it is likely that other relevant publications were not included. Also, we did not include literature written in languages other than English or gray literature. Such studies in other languages may be a significant source for information.

\section{Conclusion}

The purpose of this scoping review was to understand (a) use of videos and/or other digital media in parentimplemented interventions; (b) use of videos and/or other 
digital media in asynchronous content; (c) the role of the parent as learner; and (d) the program impact on parents and children. The limited studies that use videos and/or other digital media in asynchronous instructional content or selfmanaged programs suggest that more program development and evaluation are needed to provide accessible parentimplemented interventions.

\section{Compliance with Ethical Standards}

Conflict of Interest The authors declare that they have no conflict of interest.

Ethical Approval This research did not involve human participants and/or animals. The study used published research as a part of this scoping review.

Publisher's note Springer Nature remains neutral with regard to jurisdictional claims in published maps and institutional affiliations.

\section{References}

Allen, J., \& Marshall, C. (2011). Parent-Child Interaction Therapy (PCIT) in school-aged children with specific language impairment. International Journal of Language \& Communication Disorders, 46(4), 1-14. https://doi.org/10.3109/13682822.2010. 517600.

Andersson, G. (2018). Internet interventions: past, present and future. Internet Interventions, 12, 181-188. https://doi.org/10.1016/j. invent.2018.03.008.

Arksey, H., \& O’Malley, L. (2005). Scoping studies: towards a methodological framework. International Journal of Social Research Methodology, 8(1), 19-32. https://doi.org/10.1080/ 1364557032000119616.

Baxendale, J., \& Hesketh, A. (2003). Comparison of the effectiveness of the Hanen Parent Programme and traditional clinic therapy. International Journal of Language \& Communication Disorders, 38(4), 397-415. https://doi.org/10.1080/1368282031000121651.

Bernthal, J., Bankson, N., \& Flipson, P. (2017). Articulation and phonological disorders. 8th edition Boston: Allyn and Bacon.

Beukes, E. W., Vlaescu, G., Manchaiah, V., Baguley, D. M., Allen, P. M., Kaldo, V., \& Andersson, G. (2016). Development and technical functionality of an Internet-based intervention for tinnitus in the UK. Internet Interventions, 6, 6-15. https://doi.org/ 10.1016/j.invent.2016.08.002.

Brown, J. A., \& Woods, J. J. (2015). Effects of a triadic parentimplemented home-based communication intervention for toddlers. Journal of Early Intervention, 37(1), 44-68. https://doi.org/ $10.1177 / 1053815115589350$.

Cason, J. (2009). A pilot telerehabilitation program: delivering early intervention services to rural families. International Journal of Telerehabilitation, 1(1), 29 https://doi.org/10.5195/ijt.2009.6007.

Cason, J., Behl, D., \& Ringwalt, S. (2012). Overview of states' use of telehealth for the delivery of early intervention (IDEA Part C) services. International Journal of Telerehabilitation, 4(2), 39 https://doi.org/10.5195/IJT.2012.6105.

Christian, K., Morrison, F. J., \& Bryant, F. B. (1998). Predicting kindergarten academic skills: interactions among child care, maternal education, and family literacy environments. Early Childhood Research Quarterly, 13(3), 501-521. https://doi.org/ 10.1016/S0885-2006(99)80054-4.
Cook, D. A., \& Dupras, D. M. (2004). A practical guide to developing effective web-based learning. Journal of general internal medicine, 19(6), 698-707.

Cummins, K., \& Hulme, S. (1997). Video-a reflective tool. Speech and Language Therapy in Practice, 4-7.

Deci, E. L., \& Ryan, R. M. (1982). Intrinsic motivation inventory [measurement instrument].

DeVeney, S. L., Hagaman, J. L., \& Bjornsen, A. L. (2017). Parentimplemented versus clinician-directed interventions for latetalking toddlers: a systematic review of the literature. Соттиnication Disorders Quarterly, 39(1), 293-302. https://doi.org/10. 1177/1525740117705116.

Epstein, R., \& Street, R. (2011). The values and value of patientcentered care. The Annals of Family Medicine, 9(2), 100-103. https://doi.org/10.1370/afm.1239.

Falkus, G., Tilley, C., Thomas, C., Hockey, H., Kennedy, A., Arnold, T., \& Shah, R. (2016). Assessing the effectiveness of parent-child interaction therapy with language delayed children: a clinical investigation. Child Language Teaching and Therapy, 32(1), 7-17. https://doi.org/10.1177/0265659015574918.

Felsenfeld, S., Broen, P., \& McGue, M. (1992). A 28-year follow-up of adults with a history of moderate phonological disorder: Linguistic and personality results. Journal of Speech, Language, and Hearing Research, 35(5), 1114-1125. https://doi.org/10.1044/ jshr.3706.1341.

Friedman, M., Woods, J., \& Salisbury, C. (2012). Caregiver coaching strategies for early intervention providers: moving toward operational definitions. Infants \& Young Children, 25(1), 62-82. https://doi.org/10.1097/IYC.0b013e31823d8f12.

Girolametto, L., Pearce, P., \& Weitzman, E. (1996). Interactive focused stimulation for toddlers with expressive vocabulary delays. Journal of Speech, Language, and Hearing Research, 39 (6), 1274-1283. https://doi.org/10.1044/jshr.3906.1274.

Haskill, A., \& Tyler, A. (2007). A comparison of linguistic profiles in subgroups of children with specific language impairment. American Journal of Speech-Language Pathology, 16(3), 209-221. https://doi.org/10.1044/1058-0360(2007/026).

Hart, B., \& Risley, T. R. (1995). Meaningful differences in the everyday experience of young American children. Paul $\mathrm{H}$ Brookes Publishing.

Heath, S. B. (1982). What no bedtime story means: narrative skills at home and school. Language in Society, 11(1), 49-76. https://doi. org/10.2307/4167291.

Kaiser, A. P., \& Hampton, L. H. (2017). Enhanced milieu teaching. In R. J. McCauley, M. E. Fey \& R. B. Gillam (Eds), Treatment of language disorders in children. 2nd ed. (pp. 87-120). Baltimore, MD: Brookes.

Knowles, M. (1984). Andragogy in Action. San Francisco: Jossey-Bass.

Knowles, M. S., Holton, E. F., \& Swanson, R. A. (2005). The adult learner: the definite classic in adult education and human resource development. 6th ed. London, England: Elsevier.

Konza, D., Maloney, C., \& Grafton, P. (2010). It takes two to talk: a focused intervention program for parents and children with language delays. International Journal of Interdisciplinary Social Sciences, 5(6), 225-236.

Kuo, A. A., Franke, T. M., Regalado, M., \& Halfon, N. (2004). Parent report of reading to young children. Pediatrics, 113(5), 1944-1951.

Law, J., Boyle, J., Harris, F., Harkness, A., \& Nye, C. (2000). Prevalence and natural history of primary speech and language delay: findings from a systematic review of the literature. International Journal of Language and Communication Disorders, 35 (2), 165-188.

Leong, S. L., Baldwin, C. D., \& Adelman, A. M. (2003). Integrating Web-based computer cases into a required clerkship: development and evaluation. Academic Medicine, 78(3), 295-301. 
Levac, D., Colquhoun, H., \& O’Brien, K. K. (2010). Scoping studies: advancing the methodology. Implementation science, 5(1), 69.

Lyytinen, P., Laakso, M. L., \& Poikkeus, A. M. (1998). Parental contribution to child's early language and interest in books. European Journal of Psychology of Education, 13(3), 297.

Manolson, A. (1992). It takes two to talk. The Hanen Centre Program Manual-Second edition. Toronto: The Hanen Centre.

McCollum, J. A., \& Yates, T. J. (1994). Dyad as focus, triad as means: A family-centered approach to supporting parent-child interactions. Infants \& Young Childre, 6(4), 54-63.

McCormack, J., Harrison, L. J., McLeod, S., \& McAllister, L. (2011). A nationally representative study of the association between communication impairment at 4-5 years and children's life activities at 7-9 years. Journal of Speech, Language, and Hearing Research, 54(4), 1328-1348. https://doi.org/10.1044/ 1092-4388(2011/10-0155).

Norbury, C., \& Bishop, D. (2003). Narrative skills of children with communication impairments. International Journal of Language \& Communication Disorders, 38(3), 287-313. https://doi.org/10. 1080/136820310000108133.

Olson, K. B., Wilkinson, C. L., Wilkinson, M. J., Harris, J., \& Whittle, A. (2016). Texts for talking: evaluation of a mobile health program addressing speech and language delay. Clinical pediatrics, 55(11), 1044-1049. https://doi.org/10.1177/0009922816664721.

Orlikoff, R. F., Schiavetti, N. H., \& Metz, D. E. (2015). Evaluating research in communication disorders. 7th edition Boston: Allyn \& Bacon.

Owens, R. (2014). Language disorders: a functional approach to assessment and intervention.6th edition. Boston, MA: Allyn \& Bacon.

Pratt, A. S., Justice, L. M., Perez, A., \& Duran, L. K. (2015). Impacts of parent-implemented early-literacy intervention for Spanishspeaking children with language impairment. International Journal of Language \& Communication Disorders, 50(5), 569-579. https://doi.org/10.1111/1460-6984.12140.

Prelock, P. A., \& Hutchins, T. (2008). The role of family-centered care in research: supporting the social communication of children with ASD. Topics in Language Disorders, 28(4), 323-339. https://doi. org/10.1097/01.TLD.0000341127.93533.bd.

Richmond, T., Peterson, C., Cason, J., Billings, M., Terrell, E. A., Lee, A. C. W., \& Brennan, D. (2017). American Telemedicine Association's principles for delivering telerehabilitation services. International journal of telerehabilitation, 9(2), $63 \mathrm{https} / / / \mathrm{doi}$. org/10.5195/ijt.2017.6232.

Ritterband, L. M., Thorndike, F. P., Cox, D. J., Kovatchev, B. P., \& Gonder-Frederick, L. A. (2009). A behavior change model for internet interventions. Annals of Behavioral Medicine, 38(1), 18-27. https://doi.org/10.1007/s12160-009-9133-4.

Roberts, M. Y., Curtis, P. R., Sone, B. J., \& Hampton, L. H. (2019). Association of parent training with child language development: a systematic review and meta-analysis. JAMA pediatrics, 173(7), 671-680. https://doi.org/10.1001/jamapediatrics.2019.1197.

Roberts, M., \& Kaiser, A. (2011). The effectiveness of parentimplemented language interventions: a meta-analysis. American Journal of Speech-Language Pathology, 20, 180-189. https://doi. org/10.1044/1058-0360(2011/10-0055).

Roberts, M., \& Kaiser, A. (2012). Assessing the effects of a parentimplemented language intervention for children with language impairments using empirical benchmarks: A pilot study. Journal of Speech, Language, and Hearing Research, 55, 1655-1670. https://doi.org/10.1044/1092-4388(2012/11-0236).

Shriberg, L. D., Kwiatkowski, J., Best, S., Terselic-Weber, B., \& Hengst, J. (1986). Characteristics of children with phonologic disorders of unknown origin. Journal of Speech and Hearing Disorders, 51(2), 140-161. https://doi.org/10.1044/jshd.5102.140.

Shriberg, L. D., Tomblin, J. B., \& McSweeny, J. L. (1999). Prevalence of speech delay in 6-year-old children and comorbidity with language impairment. Journal of Speech, Language, and Hearing Research, 42(6), 1461-1481. https://doi.org/10.1044/jslhr.4206. 1461.

Snodgrass, M. R., Chung, M. Y., Biller, M. F., Appel, K. E., Meadan, H., \& Halle, J. W. (2017). Telepractice in speech-language therapy: The use of online technologies for parent training and coaching. Communication Disorders Quarterly, 38(4), 242-254. https://doi.org/10.1177/1525740116680424.

Sugden, E., Baker, E., Munro, N., \& Williams, A. L. (2016). Involvement of parents in intervention for childhood speech sound disorders: a review of the evidence. International Journal of Language \& Communication Disorders, 51(6), 597-625. https:// doi.org/10.1111/1460-6984.12247.

Tamis-LeMonda, C. S., Bornstein, M. H., \& Baumwell, L. (2001). Maternal responsiveness and children's achievement of language milestones. Child development, 72(3), 748-767. https://doi.org/ 10.1111/1467-8624.00313.

Thornton, L., Batterham, P. J., Fassnacht, D. B., Kay-Lambkin, F., Calear, A. L., \& Hunt, S. (2016). Recruiting for health, medical or psychosocial research using Facebook: systematic review. Internet Interventions, 4, 72-81. https://doi.org/10.1016/j.invent. 2016.02.001.

van Balkom, H., Verhoeven, L., van Weerdenburg, M., \& Stoep, J. (2010). Effects of parent-based video home training in children with developmental language delay. Child Language Teaching and Therapy, 26 (3), 221-237. https://doi.org/10.1177/0265659009349978.

van Eerdenbrugh, S., Packman, A., Onslow, M., O’brian, S., \& Menzies, R. (2018). Development of an internet version of the Lidcombe Program of early stuttering intervention: a trial of Part 1. International Journal of Speech-Language Pathology, 20(2), 216-225. https://doi.org/10.1080/17549507.2016.1257653.

Vismara, L. A., McCormick, C. E., Wagner, A. L., Monlux, K., Nadhan, A., \& Young, G. S. (2018). Telehealth parent training in the Early Start Denver Model: results from a randomized controlled study. Focus on Autism and Other Developmental Disabilities, 33(2), 67-79. https://doi.org/10.1177/1088357616651064.

Wake, M., Tobin, S., Girolametto, L., Ukoumunne, O. C., Gold, L., Levickis, P., \& Reilly, S. (2011). Outcomes of population based language promotion for slow to talk toddlers at ages 2 and 3 years: Let's Learn Language cluster randomised controlled trial. Bmj, 343, d4741. https://doi.org/10.1136/bmj.d4741.

Williams, G. C., \& Deci, E. L. (1996). Internalization of biopsychosocial values by medical students: a test of self-determination theory. Journal of personality and social psychology, 70(4), 767 https://doi.org/10.1037/0022-3514.70.4.767.

Wren, Y., Miller, L. L., Peters, T. J., Emond, A., \& Roulstone, S. (2016). Prevalence and predictors of persistent speech sound disorder at eight years old: findings from a population cohort study. Journal of Speech, Language, and Hearing Research, 59 (4), 647-673. https://doi.org/10.1044/2015_JSLHR-S-14-0282.

Zevenbergen, A., \& Whitehurst, G. (2003). Dialogic reading: a shared picture book reading intervention for preschoolers. In A. Van Kleeck, S. Stahl, \& E. Bauer (eds), On reading books to children: Parents and teachers, pp. 177-200. Lawrence Erlbaum.

Zubrick, S. R., Taylor, C. L., Rice, M. L., \& Slegers, D. W. (2007). Late language emergence at 24 months: an epidemiological study of prevalence, predictors, and covariates. Journal of Speech, Language, and Hearing Research, 50(6), 1562-1592. https://doi. org/10.1044/1092-4388(2007/106). 